\title{
Resilience and its relation to change in the oral health self-perception in independent older people from the southern of Brazil
}

\begin{abstract}
The existing relationship between change in oral health perception and resilience is insufficiently explored in the literature. The aim of this study was to describe the dynamics of changes in self-perception related to oral health (improvement or decline) and to evaluate the determinants of these changes in older people from Carlos Barbosa, southern Brazil. This is a cohort study whereby 587 people aged 60 years or older were evaluated in 2008. The follow-up was made in 2012, when 389 older people were evaluated. Participants completed an oral health and socio-demographic questionnaire (answers were measured on the Resilience Scale), and were submitted to an oral-health exam. The changes of self-perception related to their oral health between 2008 and 2012 were categorized as decrement, stability, and increment. In order to analyze the factors associated with the changes in self-perception related to oral health in independently living older people, a hierarchical analysis was created through multinomial regression. When it came to the change of self-perception related to their oral health, the patients experienced decrement $21.9 \%$ of the time, remained stable $48.1 \%$ of the time, and experienced increment $30.0 \%$ of the time. Access to the oral services $(\mathrm{OR}=6.00, \mathrm{CI}=1.24-28.88)$ and co-morbidities $(\mathrm{OR}=3.42, \mathrm{CI}=1.08$ $10.81)$ were associated with improvement. Resilience $(\mathrm{OR}=9.66, \mathrm{CI}=1.21-77.08)$ was associated with the decline in self-perception related to oral health. It was therefore concluded that there is a relationship between the ideas of flexibility and adjustment that is inserted into the concept of resilience and the manner in which an individual perceives his or her oral health.
\end{abstract}

Keywords: aged, longitudinal studies, psychological resilience, self-perception, oral health
Volume 10 Issue 2 - 2019

\author{
Andressa S Bez,' Luísa Helena do NTôrres, ${ }^{2}$ \\ Aline B Martins, ${ }^{3}$ Matheus Neves, ${ }^{4}$ Fernando \\ N Hugo, ${ }^{5}$ Juliana B Hilgert, ${ }^{5,6}$ \\ 'Postgraduate Studies Program in Dentistry, Federal University \\ of Rio Grande do Sul, Brazil \\ ${ }^{2}$ Faculty of Dentistry, Federal University of Santa Maria, Brazil \\ ${ }^{3}$ Postgraduate Studies Program in Public Health, Federal \\ University of Rio Grande do Sul, Brazil \\ ${ }^{4}$ Department of Preventive and Social Dentistry, Faculty of \\ Dentistry, Federal University of Rio Grande do Sul, Brazil \\ ${ }^{5}$ Postgraduate Program in Dentistry, Federal University of Rio \\ Grande do Sul, Brazil \\ ${ }^{6}$ Postgraduate Program in Epidemiology, Federal University of \\ Rio Grande do Sul, Brazil
}

Correspondence: Juliana B Hilgert, Federal University of Rio Grande do Sul, Faculty of Dentistry, Department of Preventive and Social Dentistry Rua Ramiro Barcelos 2492, Porto Alegre 90035-003, Brazil, Email jhilgert@gmail.com

Received: March 12, 2019 | Published: March 29, 2019

\section{Introduction}

Positive self-perception of health in older people is seen as an indicator of healthy aging and strengthens the processes of selfacceptance and self-regulation of the individual, besides promoting an increase in levels of social interaction, self-esteem, and wellbeing. ${ }^{1}$ Environment, attitudes, and thoughts may have an influence in the perception of oral health. ${ }^{2}$ The measurements of oral health are historically derived from models based on prevalent injuries to oral health. However, among older people the subjective aspects need to be evaluated for two reasons: Firstly, so that better predictors of outcomes related to health can be determined; and secondly, because they may have negative influences on the perception of oral health, considering the psychosocial aspects. ${ }^{3}$ Among the psychosocial concepts regarding aging, there is the idea of resilience. Resilience is a multidimensional construct and can be understood from different views: It can be seen as an individual characteristic, a process, or a result. ${ }^{4}$ Independently of the view adopted, it is clear that the capacity of a human being to answer the demands of everyday life in a positive way, despite the adversities faced along his or her vital cycle of development, ${ }^{5}$ fulfills a protective role even if the individual shows negative outcomes of health. ${ }^{6}$ As it relates to oral health, although data from SB Brasil showed improvement in the condition of the Brazilian population in 2010 , the situation remains precarious. ${ }^{7}$ However, other studies show that in spite of the extensive number of individuals experiencing tooth loss and the wide need for dental prostheses, most of the older population describe their oral health as good. The first follow-up of the cohort in 2008, showed that, although oral conditions may have been unfavorable, the self-perception was good, leading to one of the hypotheses conceived in the comprehension of such a paradox, which is that resilience influences the perception of oral health. ${ }^{7}$ It was noticed that there is little research about resilience in older people that considers oral health as apredisposing factor in order to "be resilient." When the positive self-perception of oral health is evaluated, it is realized that older people with high potential for resilience evaluate their oral health in a favorable way, even if the condition of their oral health is unfavorable. ${ }^{7}$ From this finding, it can be seen that there is a need to describe the dynamics of self-perception change related to oral health (improvement/worsening) and to evaluate the determinant factors of these changes in older people from southern Brazil. Therefore, this study is a pioneering longitudinal investigation of the relation between resilience and self-perception of oral health. For this reason, follow-ups with the older people who were evaluated in the study were made with the purpose of investigating possible changes in their self-perception related to their oral health and to establish whether resilience is associated with such changes. From this panoramic view, it was supposed that resilience may influence the change of self-perception of oral health independently of factors related to oral health. 


\section{Methods}

This study is a prospective cohort study. In 2004 (baseline), it was made a research goal to evaluate the relationship between the condition of oral health and the psychological, behavioral, and sociodemographic traits of a sample of independent, older people from Carlos Barbosa, RS, Brazil. The representativeness of the participants conformed to the social and demographic data about the population of older people from Carlos Barbosa. For more details, Hilgert. ${ }^{8}$ The first follow-up of the cohort from 2004 was made in 2008, and it was the first measurement of resilience in the sample group. Therefore, this study measured the variation of perceptions of oral health and its possible determinants between 2008 and 2012. In 2012, the second follow-up of the cohort from 2004 was made. From baseline to 2008, there was a reduction of $33.8 \%$ of the sample population, having had 587 older people in this time. The participants from the baseline and from the first follow-up in 2008 were invited to participate again in the study in 2012. Participants from the baseline were excluded from the study if they had moved from the city, started living in long-term care institutions, were hospitalized, were incapable of answering the questionnaire, were not able to move, or had died. In the follow-up of 2012 , a total of 389 older people were evaluated. The final sample size specifically for this study was 343 older people.

\section{Measures}

\section{Measures from the baseline}

The data-collecting methods included interviews with a structured questionnaire and oral-health examinations.

\section{Behavioral and sociodemographic variables, dental and medical history}

The behavioral and sociodemographic information included age, gender, location of residence, and marital status. Resilience was measured using the Resilience Scale, ${ }^{9}$ which was developed by Wagnild and Young in 1993 and was validated in Brazilian Portuguese by Pesce et al. in 2005. ${ }^{10}$ Scores of resilience are according to Wagnild. ${ }^{11}$ The resilience analyzed in this study is related to the year 2008. Other aspects analyzed were co-morbidity, schooling, personal monthly income, and participation in third-age groups. Frequencies of toothbrushing, smoking, use of alcohol, changes in diet, and tooth loss were also analyzed.

\section{Evaluation of self-perception related to the oral health}

The question to be answered was: "How do you evaluate your oral health?" The answers "excellent," "very good and good" were categorized as "good" and the answers "reasonable" and "bad" were categorized as "bad."

\section{Oral examination}

The oral status of each patient was evaluated using the DMF-T index, according to the criteria of the World Health Organization. ${ }^{12}$ The sum of teeth classified as M (lost because of caries, periodontitis, or other reasons) was used to calculate the number of missing teeth by participant. The presence of prostheses was reported according to the criteria of the $\mathrm{WHO}^{12}$ and categorized as removable total prostheses, another kind of prostheses, or without prostheses.

\section{Measure of following}

Interviews were made with a structured questionnaire. The participants were informed about the goals of the study and they were invited to sign the Informed Consent Form. Then, the questionnaire was applied by trained researchers during the year of 2012 .

\section{Evaluation of self-perception related to the oral health}

For the evaluation of change of self-perception related to oral health, a categorization system was selected in order to quantify the changes in the answers to the question of self-perception in oral health:

1. The "worse" category in self-perception related to oral health was defined as a negative answer given in the follow-up to the detriment of a positive answer in the baseline. Change in the answer from "good" to "bad" meant "worse" in a subject's selfperception related to oral health.

2. The "stability" category in self-perception related to oral health was defined as equivalence to the answers "good" or "bad" in the follow-up or in the baseline.

3. The "improvement" category in self-perception related to oral health was defined as a positive answer in the follow-up to the detriment of a negative answer in the baseline. Change in the answer from "bad" to "good" meant "improvement" in selfperception related to oral health.

The descriptive analyses of the variables were made. The categorical variables were analyzed by the chi-square test. The reability of the DMF-T inter- and intra-examiners, at the beginning and during the study, was made through the calculation of the Cohen kappa coefficient. In order to analyze the factors associated with the changes in self-perception related to oral health in independent older people, a hierarchical model was made using the theoretical model proposed by Andersen \& Davidson. According to this model, the primary determinants of oral health influence the behaviors of oral health, which are dependent variables that in turn influence the perceptions of oral health. In this study, some modifications were introduced in the model proposed by Andersen and Davidson.

Initially, the hierarchical approach included univariate nominal regressions that were made in order to verify the measured effects of each studied variable in relation to the studied outcome. After this, the multivariate analysis using nominal regression was made inside of each level. For the subsequent analysis, those variables that remained were kept associated with the outcome $\mathrm{p}<.10$ after the adjustments for the variables of the same level and for those hierarchically superior. Finally, only the variables that had $\mathrm{p}<.10$ were added in a totally adjusted model. In the totally adjusted model the associations with $\mathrm{p}<.05$ was considered significant. The analyses were made using the SPSS 18.0 statistical analysis software. This study was made after the approval of the Committee of Ethics in Research of the Piracicaba Dental School of the University of Campinas (protocol 017/2011) and referee of the Committee of Research of the Federal University of Rio Grande do Sul, and after all the participants signed the informed consent form.

\section{Results}

The average age of the study sample was $69.77( \pm 5.41)$ years, $271(68.4 \%)$ participants were female, $279(47.9 \%)$ had less than 4 years of education, and 307 (52.1\%) had income of a minimum wage (MW). In relation to the resilience score, $284(57.6 \%)$ participants showed moderate potential for resilience. Around $22 \%$ of the individuals reported worse, $48 \%$ remained stable, and $30 \%$ of the individuals reported improvement in their self-perception related to their oral health. In the baseline, the level of agreement inter- and intra-examiners (Kappa) for the DMF-T before the study ranged from 
0.97 and 1. The inter- and intra-examiners' Kappa coefficient for the DMF-T ranged from 0.91 to 0.98 during the study. The frequencies of the independent variables estimated in the study in relation to the change of self-perception of oral health are shown in Table 1 . The results of the univariate analysis are shown in Table 2. In the totally adjusted hierarchical model (Table 3 ), resilience (moderate potential) kept its association with the outcome worse for perception of oral health $(\mathrm{p}=.032)$. It was observed that the odds ratio $(\mathrm{OR})$ was 9.66 in the variable "moderate potential of resilience" as it related to the variables "high potential of resilience" and "worse of self-perception of oral health," being the CI of $95 \%$ between the values $1.21-77.08$. Therefore, those who had a moderate potential of resilience in the study sample had a 9.66-times greater chance of getting worse in his or her perception of oral health when compared to those whom had high potential of resilience. Co-morbidities ( $\leq 2$ diseases) $(\mathrm{OR}=6.00$, $\mathrm{CI}=1.24-28)$ and use of dental service (never) $(\mathrm{OR}=3.42$; $\mathrm{IC}=1.08$ 10.81) were associated significantly with the improvement in the perception of oral health.

Table I Description of the sample studied according to the change of self-perception of oral health $(n=343)$

\begin{tabular}{|c|c|c|c|c|c|c|}
\hline Block & Variable & Worse N (\%) & Stable N (\%) & Improvement N (\%) & $\mathbf{N}^{*}$ & $\mathbf{p}$ \\
\hline$I^{\circ}$ Block & Age (years) (2008) & & & & & \\
\hline \multirow[t]{7}{*}{ Variables Exogenous } & 63 to 65 & $23(30.7)$ & $40(24.2)$ & $22(21.4)$ & 343 & 0.089 \\
\hline & 66 to 68 & $10(26.7)$ & $3 I(18.8)$ & $3 I(30.1)$ & & \\
\hline & 69 to 73 & $16(21.3)$ & $5 I(30.9)$ & $19(18.4)$ & & \\
\hline & 74 to 87 & $16(21.3)$ & $43(26.1)$ & $3 I(30.1)$ & & \\
\hline & Gender & & & & & \\
\hline & Male & $22(29.3)$ & $55(33.3)$ & $35(34.0)$ & 343 & 0.781 \\
\hline & Female & $53(70.7)$ & $110(69.7)$ & $68(66.0)$ & & \\
\hline $2^{\circ}$ Block & Location of the residence & & & & & \\
\hline \multirow[t]{20}{*}{ Primary Determinants } & Urban & $44(58,7)$ & $92(55,8)$ & $50(48,5)$ & 343 & 0.351 \\
\hline & Rural & $3 I(4 I, 3)$ & $73(44,2)$ & $53(5 I, 5)$ & & \\
\hline & Marital Status & & & & & \\
\hline & Not-married & $23(31.1)$ & $57(34.5)$ & $3 I(30.4)$ & 341 & 0.745 \\
\hline & Married & $51(68.9)$ & $108(65.5)$ & $71(69.6)$ & & \\
\hline & Resilience (2008) & & & & & \\
\hline & Low potential & $20(30.3)$ & $47(34.1)$ & $34(40.5)$ & 288 & 0.053 \\
\hline & Moderate potential & $45(68.2)$ & $75(54.3)$ & $45(53.6)$ & & \\
\hline & High potential & $\mathrm{I}(\mathrm{I} .5)$ & $16(11.6)$ & $5(6.0)$ & & \\
\hline & Co-morbidities & & & & & \\
\hline & $\leq 2$ diseases & $65(86.7)$ & $145(89.0)$ & $99(97.1)$ & 340 & 0.03 \\
\hline & $>2$ diseases & $10(13.3)$ & $18(\mid 1.0)$ & $3(2.9)$ & & \\
\hline & Schooling & & & & & \\
\hline & $\leq 4$ years & $35(48.6)$ & $72(43.6)$ & $45(43.7)$ & 340 & 0.754 \\
\hline & $>4$ years & $37(51.4)$ & $93(56.4)$ & $58(56.3)$ & & \\
\hline & Income & & & & & \\
\hline & $\leq \mathrm{IMW}$ & $48(64.0)$ & $80(48.5)$ & $59(57.3)$ & 343 & 0.065 \\
\hline & $\begin{array}{l}>1 \mathrm{MW} \\
\text { Participation in third age } \\
\text { groups }\end{array}$ & $27(36.0)$ & $85(51.5)$ & $44(42.7)$ & & \\
\hline & Yes & $43(57.3)$ & $107(66.0)$ & $68(66.7)$ & 339 & 0.359 \\
\hline & No & $32(42.7)$ & $55(34.0)$ & $34(33.3)$ & & \\
\hline $3^{\circ}$ Block & Frequency of tooth & & & & & \\
\hline \multirow[t]{4}{*}{ Behaviors of oral health } & brushing & & & & & \\
\hline & $\leq 1 \times$ day & $14(18.7)$ & $23(13.9)$ & $25(24.5)$ & 342 & 0.092 \\
\hline & $\geq 2 x$ day & $61(81.3)$ & $142(86.1)$ & $77(75.5)$ & & \\
\hline & Smoking status & & & & & \\
\hline
\end{tabular}


Table Continued...

\begin{tabular}{|c|c|c|c|c|c|c|}
\hline Block & Variable & Worse N (\%) & Stable N (\%) & Improvement N (\%) & $\mathbf{N} *$ & $\mathbf{p}$ \\
\hline & No & $7 I(94.7)$ & 156(94.5) & $100(97.1)$ & 343 & 0.601 \\
\hline & Yes & $4(5.3)$ & $9(5.5)$ & $3(2.9)$ & & \\
\hline & \multicolumn{6}{|l|}{ Use of alcohol } \\
\hline & Yes & $44(58.7)$ & $94(57.0)$ & $58(56.9)$ & 342 & 0.964 \\
\hline & No & $3 I(4 \mid .3)$ & $7 I(43.0)$ & $44(43.1)$ & & \\
\hline & \multicolumn{6}{|l|}{ Change of diet } \\
\hline & Yes & $22(29.3)$ & $59(35.8)$ & $35(34.0)$ & 343 & 0.621 \\
\hline & No & $53(70.7)$ & $106(64.2)$ & $68(66.0)$ & & \\
\hline & \multicolumn{6}{|c|}{ Use of dental service } \\
\hline & Never & $19(25.3)$ & $25(15.2)$ & $36(36.4)$ & 338 & 0.001 \\
\hline & Problem oriented & $43(57.3)$ & II $2(74.4)$ & $55(55.6)$ & & \\
\hline & Regularly & $13(17.3)$ & $17(10.4)$ & $8(8.1)$ & & \\
\hline \multirow{5}{*}{$\begin{array}{l}4^{\circ} \text { Block Condition of oral } \\
\text { health }\end{array}$} & \multicolumn{6}{|c|}{ Dental loss in the last 4 years } \\
\hline & \multicolumn{6}{|l|}{ Edentulous } \\
\hline & Loss & $36(48.6)$ & $78(47.6)$ & $58(56.9)$ & 340 & 0.614 \\
\hline & \multirow[t]{2}{*}{ Not Loss } & $12(16.2)$ & $31(18.9)$ & I4(I3.7) & & \\
\hline & & $26(35.1)$ & $55(33.5)$ & $30(29.4)$ & & \\
\hline
\end{tabular}

*Number of individuals in each category

Table 2 Univariate analyses-change in the self-perception related to the oral health

\begin{tabular}{|c|c|c|c|c|c|}
\hline \multirow[t]{2}{*}{ Block } & \multirow[t]{2}{*}{ Variable } & \multicolumn{2}{|c|}{$\begin{array}{l}\text { Worse in the self-perception related } \\
\text { to the oral health }\end{array}$} & \multicolumn{2}{|c|}{$\begin{array}{l}\text { Improvement in the self-perception related } \\
\text { to the oral health }\end{array}$} \\
\hline & & Crude OR (95\%Cl) & $\mathbf{p}$ & Crude OR (95\%Cl) & $\mathbf{p}$ \\
\hline \multirow{7}{*}{$I^{\circ}$ Block Variables exogenous } & 63 to 65 & I.54(0.7I-3.33) & 0.268 & $0.76(0.38-I, 53)$ & 0.446 \\
\hline & 66 to 68 & I.73(0.77-3.87) & 0.179 & I.38(0.70-2,73) & 0.345 \\
\hline & 69 to 73 & $0.84(0.37-1.88)$ & 0.677 & $0.5 I(0.25-I, 04)$ & 0.065 \\
\hline & 74 to 87 & 1 & & 1 & \\
\hline & \multicolumn{5}{|l|}{ Gender } \\
\hline & Male & $0.83(0.45-1.50)$ & 0.539 & $\mathrm{I} .02(0.6 \mathrm{I}-\mathrm{I} .73)$ & 0.913 \\
\hline & female & I & & 1 & \\
\hline \multirow[t]{12}{*}{$2^{\circ}$ Block Primary Determinants } & \multicolumn{5}{|c|}{ Location of the residence } \\
\hline & urban & I.I2(0.64-I.95) & 0.673 & $0.74(0.45-1.22)$ & 0.25 \\
\hline & rural & 1 & & 1 & \\
\hline & \multicolumn{5}{|l|}{ Marital Status } \\
\hline & Not-married & $0.85(0.47-1.53)$ & 0.6 & $0.82(0.48-I .40)$ & 0.483 \\
\hline & married & I & & 1 & \\
\hline & \multicolumn{5}{|l|}{ Resilience } \\
\hline & Low & $6.80(0.84-54.87)$ & 0.072 & $2.31(0.77-6.93)$ & 0.134 \\
\hline & Moderate & $9.60(1.23-74.85)$ & 0.031 & $1.92(0.65-5, .9)$ & 0,232 \\
\hline & High & 1 & & 1 & \\
\hline & \multicolumn{5}{|c|}{ Co-morbidities } \\
\hline & $\leq 2$ diseases & $0.80(0.35-1.84)$ & 0.611 & $4.09(1.17-14.27)$ & 0.027 \\
\hline
\end{tabular}

Citation: Bez AS, Tôrres LHN, Martins AB, et al. Resilience and its relation to change in the oral health self-perception in independent older people from the southern of Brazil.J Dent Health Oral Disord Ther. 20I9; I0(2): I40-147. DOI: 10.15406/jdhodt.2019.10.00475 
Table Continued...

\begin{tabular}{|c|c|c|c|c|c|}
\hline \multirow[t]{2}{*}{ Block } & \multirow[t]{2}{*}{ Variable } & \multicolumn{2}{|c|}{$\begin{array}{l}\text { Worse in the self-perception related } \\
\text { to the oral health }\end{array}$} & \multicolumn{2}{|c|}{$\begin{array}{l}\text { Improvement in the self-perception related } \\
\text { to the oral health }\end{array}$} \\
\hline & & Crude OR (95\%CI) & $\mathbf{p}$ & Crude OR (95\%CI) & $\mathbf{p}$ \\
\hline & Income & & & & \\
\hline & $\leq I M W$ & I.88(I.07-3.3I) & 0.026 & $\mathrm{I} .42(0.86-2.33)$ & 0.162 \\
\hline & Participation & third age groups & & & \\
\hline & Yes & $0.69(0.39-\mid .2 I)$ & 0.196 & $\mathrm{I} .02(0.60-\mathrm{I} .73)$ & 0.918 \\
\hline & No & 1 & & I & \\
\hline \multirow[t]{16}{*}{$3^{\circ}$ Block Behaviors of oral health } & \multicolumn{5}{|c|}{ Frequency of tooth brushing } \\
\hline & $\leq 1 \times$ day & I.4I (0.68-2.93) & 0.349 & $2.00(1.06-3.76)$ & 0.031 \\
\hline & $\geq 2 x$ day & 1 & & I & \\
\hline & \multicolumn{5}{|c|}{ Smoking status } \\
\hline & No & $1.02(0.30-3.43)$ & 0.969 & $1.92(0.50-7.27)$ & 0.335 \\
\hline & Yes & I & & I & \\
\hline & \multicolumn{5}{|c|}{ Use of alcohol } \\
\hline & Yes & $1.07(0.61-1.86)$ & 0.805 & $0.99(0.60-1.63)$ & 0.986 \\
\hline & No & I & & 1 & \\
\hline & \multicolumn{5}{|c|}{ Change of diet } \\
\hline & No & I.34(0.74-2.42) & 0.33 & $1.08(0.64-\mid .8 I)$ & 0.767 \\
\hline & Yes & 1 & & 1 & \\
\hline & \multicolumn{5}{|c|}{ Use of dental service } \\
\hline & Problem & $0.46(0.20-1.02)$ & 0.461 & $0.95(0.39-2.35)$ & 0.925 \\
\hline & \multicolumn{5}{|l|}{ Oriented } \\
\hline & Regularly & I & & I & \\
\hline $4^{\circ}$ Block & \multicolumn{5}{|c|}{ Dental loss in the last 4 years } \\
\hline \multirow[t]{3}{*}{ Condition of oral health } & Edentulous & $0.97(0.53-1.79)$ & 0.939 & I.36(0.77-2.38) & 0.278 \\
\hline & loss & $0.8 \mid(0,36-\mid .84)$ & 0.63 & $0.82(0.38-I .79)$ & 0.632 \\
\hline & No loss & I & & I & \\
\hline
\end{tabular}

Test: Likelihood Ratio

Table 3 Hierarchical Model totally adjusted -Worse and Improvement in the self-perception related to the oral health

\begin{tabular}{|c|c|c|c|c|}
\hline \multirow{2}{*}{ Variable } & \multicolumn{2}{|c|}{ Worse in the self-perception of oral health } & \multicolumn{2}{|c|}{ Improvement in the self-perception of oral health } \\
\hline & Adjusted OR (IC95\%) & $\mathbf{p}$ & Adjusted OR (IC95\%) & $\mathbf{p}$ \\
\hline \multicolumn{5}{|l|}{ Age (years) } \\
\hline 63 to 65 & $\mathrm{I} .40(0.58-3.34)$ & 0.449 & $0.72(0.31-1.65)$ & 0.443 \\
\hline 66 to 68 & $1.30(0.52-3.26)$ & 0.567 & I.I7 (0.5I-2.67) & 0.709 \\
\hline 69 to 73 & $0.68(0.28-1.65)$ & 0.402 & $0.48(0.20-I .13)$ & 0.096 \\
\hline 74 to 87 & I & & I & \\
\hline \multicolumn{5}{|c|}{ Co-morbidities } \\
\hline$\leq 2$ diseases & $0.71(0.26-1.94)$ & 0.513 & $6.00(1.24-28.88)$ & 0.025 \\
\hline$>2$ diseases & $\mathrm{I}$ & & $\mathrm{I}$ & \\
\hline
\end{tabular}


Table Continued...

\begin{tabular}{|c|c|c|c|c|}
\hline \multirow{2}{*}{ Variable } & \multicolumn{2}{|c|}{ Worse in the self-perception of oral health } & \multicolumn{2}{|c|}{ Improvement in the self-perception of oral health } \\
\hline & Adjusted OR (IC95\%) & $\mathbf{p}$ & Adjusted OR (IC95\%) & $\mathbf{p}$ \\
\hline \multicolumn{5}{|l|}{ Resilience } \\
\hline Low & $7.62(0.92-63.13)$ & 0.06 & $2.70(0.76-9.49)$ & 0.122 \\
\hline Moderate & $9.66(1.21-77.08)$ & 0.032 & $2.07(0.60-7.07)$ & 0.243 \\
\hline High & 1 & & I & \\
\hline \multicolumn{5}{|c|}{ Participation of third age groups } \\
\hline Yes & $0.56(0.29-1.05)$ & 0.073 & $0.82(0.44-\mid .52)$ & 0.535 \\
\hline No & I & & I & \\
\hline \multicolumn{5}{|l|}{ Use of alcohol } \\
\hline Yes & $1,09(0,58-2,07)$ & 0,776 & $0,64(0,35-I, 17)$ & 0.15 \\
\hline No & 1 & & I & \\
\hline \multicolumn{5}{|l|}{ Use of dental service } \\
\hline Never & $0.96(0.33-2.78)$ & 0.944 & $3.42(1.08-10.81)$ & 0.036 \\
\hline Problem Oriented & $0.41(0.16-1.04)$ & 0.063 & $1.00(0.34-2.91)$ & 0.992 \\
\hline Regularly & I & & I & 0.992 \\
\hline Crude OR (95\%Cl) & $\mathrm{P}$ & Crude OR (95\%Cl) & $\mathrm{P}$ & \\
\hline
\end{tabular}

\section{Discussion}

The results of this cohort study suggest that the change in selfperception of oral health suffers from the influence of several variables that integrate the proposed hierarchical model. The originality of the study lies in the evaluation of the perception of oral health, considering resilience as its modifying factor. In this study, it was noticed that a moderate degree of resilience increased the chance of a change to worse in self-perception, revealing that lower levels of resilience predisposed negative outcomes in health. On the other hand, having few diseases and never having previously used dental services are factors associated with improving self-perception, leading to the belief that the non-use is not necessarily the result of a good condition of oral health, but probably of the absence of pain and the acceptance of a condition established for a period of time. The fact that a smaller number of co-morbidities caused improvement in self-perception may have reinforced a good evaluation of health that was also felt in oral health.

In the current study, it was noticed that there is an association between individuals who had low potential of resilience and individuals who had a worse perception of their oral health; that is, people with moderate degrees of resilience saw their oral health negatively when compared to people with high levels of resilience. It was verified that there was an important difference of self-perception for these older people, who once previously had a high potential of resilience that increased the chances of a good perception of oral health. ${ }^{7}$ It is coherent, therefore, to investigate the causes of this change of self-perception and degrees of resilience of this sample, providing possibly a cohesive comprehension of this question. It was expected that there would be a change in relation to resilience, because it is well known that this psychological characteristic is not a static component of an individual, but rather it is an attribute that suffers malleability over time and as a result of individual and environmental factors, such as co-morbidity and income. According to longitudinal studies, there are other factors that differentiate individuals who have evolutionary answers that reveal their resilience and may explain, partially, the possible changes in the potential for resilience. These factors may include receptive and affective temperament, higher intellectual development, higher levels of self-esteem, more degrees of self-control, smaller families, and fewer familial conflicts. ${ }^{13,14}$ As can be seen, this study of the causal factors of changes of selfperception explains, partially, the differences found in relation to selfperception in oral health. Other evidence has shown that psychological resilience is associated directly with emotional intelligence and has points pointed out that resilient people exhibit a weak relation between unfavorable events and levels of stress due to their selfknowledge, self-control, emotional expression and - mainly - their self-esteem..$^{14}$ Therefore, the assumption can be made that people with low levels of resilience tend to have stronger association with negative events, as reported in the current study. The study found that having low levels of social and emotional welfare (such as anxiety, resilience, depression, and mental illness) is associated with some negative outcomes in oral health (capacity of toothbrushing, history of oral disease, and restricted access to dental care),${ }^{15}$ pointing to a strong relation between psychological attitudes and oral health while highlighting the complexity of this interaction. ${ }^{16}$ The concept of selfperception of health includes many components related to health status, such as physical, mental, and functional health, as well as social support. Thus, any modification in one of these components may be reflected in a change in the self-evaluation of oral health. The current study sustains this affirmation, because it has demonstrated that having two diseases is a positive factor in the evaluation of oral health; that is, older people with fewer co-morbidities tend to improve their self-perception. The literature agrees with this finding, because it shows that older people with higher levels of co-morbidities have a greater chance of perceiving their health negatively. ${ }^{17}$ Studies report that negative self-perception of health is associated with a greater prevalence of diseases, confirming that the relation between self-perception of health and chronic diseases and incapacities has mutual meaning. If there is a retro-alimentation between negative 
self-perception and decline of health, then self-perception acts as an indicator of the status of current health that may also predict future severities and functional limitations. ${ }^{18}$ Self-perception of oral health is a predictor for the self-perception of overall health. Diseases, medications, and physical limitations contribute to a weak evaluation of oral health that reflects itself in a poor self-evaluation of general health. ${ }^{19}$ As would be expected, self-evaluation of oral health is not disassociated from health in general, which suffers from the influence of the presence of systemic diseases and mental health. ${ }^{20}$ Evidence shows that having less education, being a woman, or having depression can increase the chance that an individual will have a negative selfimage of his or her oral health, ${ }^{15,21,22,23}$ but a negative self-image does not necessarily interfere in social relations. ${ }^{24}$ There is also evidence that dental factors, such as not needing a prosthesis, etc., can mitigate an unfavorable self-perception of oral appearance..$^{25}$ Previous findings were not corroborated by this study, possibly due to the fact that they were studies of transversal cohorts, besides which they did not evaluate the main variable of this study, which was resilience.

The lack of association between some variables and the outcome may be related to the homogeneity of the socioeconomic characteristics of this sample. Another factor that may have contributed to this result was that the ethnic characteristic of the sample group was mainly white. One of the challenges of the longitudinal research framework is the possibility of no follow-up contact with subjects, meaning a loss of individual participants in the study over time. In this study, characterized by a cohort of older people, the sample loss may be explained by events like death, incapacitating disease, or relocation. The construct of resilience may also have been a limiting factor, since it does not include aspects related to non-resilience. More studies in the area are needed in order for the results to be enhanced and reproduced in other contexts. Therefore, the findings of this study suggest that the moderating potential of resilience is able to increase the occurrence of a negative outcome, represented as "worse" in the self-perceptions of oral health for a sample of independent older people in Carlos Barbosa, southern Brazil. Future studies are necessary in order to clarify this association in different age groups. It is believed that psychological variables - such as resilience, among others - should be included in future studies that seek to investigate the dynamics of changes in outcomes of oral health due to the changes in the potential for resilience, as well as to investigate the influence of oral health status in possible modifications of the resilience profiles of older people.

\section{Acknowledgments}

This study was supported by Fundação de Amparo à Pesquisa do Estado de São Paulo (2011/22541-8) and by Coordenação de Aperfeiçoamento de Pessoal de Nível Superior (Scholarship for Andressa S. Bez).

\section{Confclict of interest}

The author declares taht athere is no conflci fo interest.

\section{References}

1. Kleinspehn-Ammerlahn A, Kotter-Grühn D, Smith J. Self-perceptions of ageing: do subjective age and satisfaction with ageing change during old age? J Gerontol B Psychol Sci Soc Sci. 2008;63(6):377-385.

2. Esmeriz CEC, Meneghim M, Ambrosano GMB. Self-perception of oral health in non-institutionalised elderly of Piracicaba city, Brazil. Gerodontology. 2012;29(2):e281-e289.
3. Mesas AE, de Andrade SM, Cabrera MAS. Factors associated with negative self-perception of oral health among elderly people in a Brazilian community. Gerodontology. 2008;25(1):49-56.

4. Lee TY, Cheung CK, Kwong WM. Resilience as a positive youth development construct: a conceptual review. Scientific World Journal. 2012;12:1-9.

5. Noronha MGRCS, Cardoso PS, Moraes TNP et al. Resilience : a new perspective in promoting family health? Science \& Collective Health. 2009;14(2):497-506.

6. Shen K, Zeng Y. The association between resilience and survival among Chinese elderly. Demogr Res. 2010;23(5):105-116.

7. Martins AB, dos Santos CM, Hilgert JB et al. Resilience and selfperceived oral health: a hierarchical approach. $J$ Am Geriatr Soc. 2011;59(4):725-731.

8. Hilgert JB, Hugo FN, de Sousa LM et al. Oral status and its association witih obesity in Southern Brazilian people. Gerodontology. 2009;26(1):46-52.

9. Wagnild GM, Young HM. Development and psychometric evaluation of the resilience scale. J Nurs Meas. 1993;1(2):165-177.

10. Pesce RP, Assis SG, Avanci JQ et al. Transcultural adaptation, reliability and validity of the resilience scale. Public Health Notebooks. 2005;21(2):436-448.

11. Wagnild GM. A review of the Resilience Scale. J Nur Meas. 2009;17(2):105-113.

12. WHO/World Health Organization. Towards a common language for functioning, disability and health. Geneva: World Health Organization; 2002.

13. Paula-Couto MCP, Koller SH, Novo RF. Resilience on aging: risk and protection. In: Falcão DVS, e Dias CMSB, editors. Maturity and Old age: Searches and Psychological Interventions. São Paulo: Casa do Psicólogo. 2006;314-318.

14. Armstrong AR, Galligan RF, Critchley CR. Emotional intelligence and psychological resilience to negative life events. Pers Individ Dif. 2011;51:331-336.

15. Finlayson TL. Oral health disparities and psychological correlates of self-rated oral health in the National Survey of American Life. Am J Public Health. 2010;100:S246-S255.

16. Jamieson LM, Paradies YC, Gunthorpe W et al. Oral health and social and emotional well-being in a birth cohort of Aboriginal Australian young adults. BMC Public Health. 2011;11:656-666.

17. Darviri C, Artemiadis AK, Tigani $X$, et al. Lifestyle and self-rated health: a cross-sectional study of 3.601 citizens of Athens, Greece. BMC Public Health. 2011;11:619-627.

18. Bailis DS, Segall A, Chipperfield JG. Two views of self-rated general health status. Soc Sci Med. 2003;56(2):203-217.

19. Benyamini Y, Leventhal H, Leventhal EA. Sefl-rated oral health as an independent predictor of self-rated general health, self-steem and life satisfaction. Soc Sci Med. 2004;59(5):1109-1116.

20. Martins AMEDL, Barreto SM, Pordeus IA. Self-assessment of oral health in the elderly : analysis based on a multidimensional model. Cad Saude Publica. 2009;25(2):421-435.

21. Karlsdotter K, Martín JJM, González MPLA. Multilevel analysis of income, income inequalities and health in Spain. Soc Sci Med. 2012;74(7):1099-1106.

22. Layes A, Asada Y, Kephart G. Whiners and deniers-What does self-rated health measure? Soc Sci Med. 2012;75(1):1-9. 
23. Mesas AE, de Andrade SM, Cabrera MAS. Factors associated with negative self-perception of oral health among elderly people in a Brazilian community. Gerodontology. 2008,25(1):49-56.

24. Nunes CIP, Abegg C. Factors associated with oral health perception in older Brazilians. Gerodontology. 2008;25:42-48.
25. Pattussi MP, Peres KG, Boing AF et al. Self-rated oral health and associated factors in Brazilian elders. Community Dent Oral Epidemiol. 2010;38(4):348-359. 